\title{
A window of opportunity for intensifying testing and tracing efforts to prevent new COVID-19 outbreaks due to more transmissible variants
}

\author{
Jianhong $\mathrm{Wu}^{1,2 \star}$, Francesca Scarabel ${ }^{1,2}$, Zachary McCarthy ${ }^{1,2}$, Yanyu Xiao ${ }^{3}$, Nicholas H Ogden ${ }^{4}$
}

\begin{abstract}
Background: When public health interventions are being loosened after several days of decline in the number of coronavirus disease 2019 (COVID-19) cases, it is of critical importance to identify potential strategies to ease restrictions while mitigating a new wave of more transmissible variants of concern (VOCs). We estimated the necessary enhancements to public health interventions for a partial reopening of the economy while avoiding the worst consequences of a new outbreak, associated with more transmissible VOCs.

Methods: We used a transmission dynamics model to quantify conditions that combined public health interventions must meet to reopen the economy without a large outbreak. These conditions are those that maintain the control reproduction number below unity, while accounting for an increase in transmissibility due to VOC.
\end{abstract}

Results: We identified combinations of the proportion of individuals exposed to the virus who are traced and quarantined before becoming infectious, the proportion of symptomatic individuals confirmed and isolated, and individual daily contact rates needed to ensure the control reproduction number remains below unity.

Conclusion: Our analysis indicates that the success of restrictive measures including lockdown and stay-at-home orders, as reflected by a reduction in number of cases, provides a narrow window of opportunity to intensify case detection and contact tracing efforts to prevent a new wave associated with circulation of more transmissible VOCs.
This work is licensed under a Creative Commons Attribution 4.0 International License.

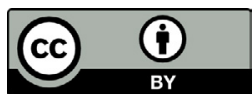

Affiliations

${ }^{1}$ Laboratory for Industrial and Applied Mathematics,

Department of Mathematics and Statistics, York University, Toronto, ON

2 Fields-CQAM Laboratory of Mathematics for Public Health, York University, Toronto, ON

${ }^{3}$ Department of Mathematical Sciences, University of Cincinnati, Cincinnati, $\mathrm{OH}$, United States

${ }^{4}$ Public Health Risk Sciences Division, National Microbiology Laboratory, Public Health Agency of Canada, St-Hyacinthe, QC

\section{${ }^{\star}$ Correspondence:} wujh@yorku.ca

Suggested citation: Wu J, Scarabel F, McCarthy Z, Xiao Y, Ogden NH. A window of opportunity for intensifying testing and tracing efforts to prevent new COVID-19 outbreaks due to more transmissible variants. Can Commun Dis Rep 2021;47(7/8):329-38. https://doi.org/10.14745/ccdr.v47i78a06

Keywords: SARS-CoV-2, variants of concern, non-pharmaceutical interventions, relaxations

\section{Introduction}

The coronavirus disease 2019 (COVID-19) pandemic extended to Canada early in 2020, and a spring wave of epidemic transmission was controlled by restrictive closures that reduced the daily rate of people contacting one another, which drove the control reproduction number below unity (1). As restrictive closures were lifted in early summer 2020 several modelling studies have identified the need for enhancement to detection and isolation of cases, and tracing and quarantine of contacts ("testing and tracing"), to maintain control of the epidemic (i.e. to either prevent the increase in case numbers, or to prevent exceeding healthcare capacity in the short and long term) (2-5). These enhancements to detection and isolation and tracing and quarantining may compensate for the increase in daily contact rates in the general population and resultant transmission associated with lifting restrictions (2-5). As we know, the epidemic did resurge at the end of 2020, suggesting that capacity for testing and tracing was insufficient to control the epidemic, and further restrictive closures were required to bring the "second wave" under control. As provinces and territories contemplate lifting restrictive closures, a new threat emerged: new, more highly transmissible variants, also known as "variants of concern" (VOCs). Several of these variants, which were first identified elsewhere in the world, are now spreading in Canada, particularly the B.1.1.7 variant. The B.1.1.7 variant expanded rapidly in the United Kingdom during the fall 2020, likely assisted by the lifting of restrictive closures as well as the 
intrinsically higher transmission rate of the new variant compared with the previously circulating virus strains (6). Here we explore what testing and tracing capacity would be needed to maintain control of the COVID-19 epidemic using data in Ontario, given that more transmissible variants are becoming or have become dominant, while vaccinations are being rolled out to the Canadian population.

\section{Intervention}

We used a transmission dynamics model (4) fitted to cumulative reported cases during the first and second wave of the COVID-19 epidemic in Ontario, Canada, to quantify conditions of combined public health interventions that could have allowed to partially reopen the economy without a large outbreak. These conditions are those that maintain the control reproduction number to remain below unity while accounting for the increased transmissibility of the VOC. These conditions must be checked before the province considers reopening again after mitigating the third wave. The approximate dates for each of the waves of COVID-19 experienced thus far in Ontario, Canada thus far are listed in Table 1.

Table 1: The three waves of COVID-19 in Ontario

\begin{tabular}{|l|l|}
\multicolumn{1}{|c|}{ Description } & \multicolumn{1}{c|}{ Approximate dates } \\
\hline Wave one (the first wave) & February 2020-August 2020 \\
\hline Wave two (the second wave) & September 2020-Mid-February 2021 \\
\hline Wave three (the third wave) & Mid-February 2021-June 2021 ${ }^{\text {a }}$ \\
\hline
\end{tabular}

As of June 2021, the time of writing, Ontario is in its third wave of COVID-19

In the model, the population is divided into susceptible $(S)$, exposed $(E)$, asymptomatic infectious $(A)$, infectious with symptoms $(I)$, and recovered $(R)$ compartments according to the epidemiological status of individuals. The model also includes diagnosed cases that are isolated $(D)$, quarantined susceptible $\left(S_{q}\right)$ and quarantined exposed $\left(E_{q}\right)$ compartments to model the impact of contact tracing (i.e. identifying and contacting people who have had physical contact with infected individuals) and quarantine of these traced contacts. Within the model framework, a proportion, $q$, of individuals exposed to the virus are traced and quarantined (the "quarantine proportion"). The resulting transmission dynamics model is a system of ordinary differential equations.

The control reproduction number was calculated as

$$
R_{c}=\frac{\beta \rho c(1-q)}{\delta_{I}+\alpha+\gamma_{I}}+\frac{\beta c \theta(1-\rho)(1-q)}{\gamma_{A}}
$$

In this formula, $c$ is the average number of daily contacts of one individual in the population, $\beta$ is the probability of transmission upon contact, $\varrho$ is the probability of having symptoms among infected individuals, $\theta$ is the relative infectiousness of asymptomatic cases, $\delta$, is transition rate of symptomatic infected individuals to the diagnosed and isolated class, $\alpha$ is the mortality rate, and $Y_{I}$ and $Y_{A}$ are the recovery rates of symptomatic and asymptomatic infected individuals, respectively. Therefore, the measures of effectiveness of testing and tracing are $\delta_{I}$ (the rate at which symptomatic people are detected and isolated) and $q$ (the proportion of contacts of cases that are traced and quarantined before they become infectious). The proportion of infectious individuals who have been missed from the contact tracing and quarantine before entering the infectious period and are tested, confirmed and then isolated during the infectious period is given by $\delta_{I} /\left(\delta_{I}+\alpha+Y_{I}\right)$. We here focus on finding conditions on $q$ and $\delta_{I} /\left(\delta_{I}+\alpha+Y_{I}\right)$, which, under different daily contacts and increased transmissibility due to the VOC, ensure $R_{c}<1$.

We obtained values for model parameters that allow $R_{c}<1$ using model fitting and data integration from multiple sources. We fit the transmission dynamics model to the cumulative reported cases in Ontario until December 23, 2020 using an established technique (4) (see Appendix) and accounted for the different phases of physical distancing in the province. Through model fitting, key values for the model were estimated. These included the proportion of cases detected and isolated, the proportion of contacts traced and quarantined, the probability of transmission on contact, infectiousness of asymptomatic cases and rates of recovery from infection. To incorporate the effect of the VOC, we modelled an increase by $40 \%$ in the probability of transmission $\beta$ compared with the values estimated before December 2020. This value of $40 \%$ is taken from the lower estimates of the increased transmissibility of the B.1.1.7 strain obtained in the United Kingdom $(6,7)$. We then investigated the case detection and contact tracing levels needed to prevent a new wave of COVID-19, assuming different increasing contact rates from three to 12 per day.

\section{Outcomes}

\section{Quantification of the evolution of physical distancing measures}

Since the beginning of the COVID-19 pandemic, like most Canadian provinces and territories, Ontario has gone through different phases of physical distancing escalation and enhanced testing for mitigating the first wave, followed by relaxation of closures to reopen the economy that led to the second wave and triggered a new second round of closures. It should be remarked that the second round of closures was also relaxed when the total cases declined but the more transmissible B.1.1.7 variant became dominant, leading to a third wave. While the quantification of the physical distancing measures in this research is based on data and analyses of the first two waves, the derived necessary conditions for reopening without a new large-scale outbreak that the Province of Ontario is experiencing clearly 
supports the call for urgent attention to enhancing the capacity for testing-to-tracing and tracing-to-quarantine/isolation in preparation for the new reopening.

The escalation of closures implemented in Ontario in 2020 for mitigating the first wave involved stages from March 2020 (Table 2). The reopening process was more region-specific, but in general had three main stages: Phase 1, 2 and 3 reopening. Subsequently, enhanced measures began to be re-implemented in the province following Stage 3 reopening in fall 2020. The specific timeline which captures the essence of key events and is considered in this modelling study is shown in Table 2. In this study, December 23 marked the end date of data fitting, taken as the last day of data preceding the province-wide lockdown and not heavily affected by the Christmas festivities. The data fitting procedure (detailed in Appendix) also captured the effects of additional key events in the timeline related to the probability of transmission, case detection and contact tracing. In several regions, a requirement for the usage of face masks or coverings in enclosed public spaces was effective on July 7, 2020. Also, the variations in testing volumes, contact tracing and case detection during October 8-22, 2020 were quantified.

Table 2: Phases of physical distancing escalation and relaxations in Ontario, Canada

\begin{tabular}{|l|l|}
\hline \multicolumn{1}{|c|}{ Description } & \multicolumn{1}{c|}{ Date } \\
\hline School closure until emergency declaration & March 14-18, 2020 \\
\hline $\begin{array}{l}\text { Emergency declaration until the closure of } \\
\text { non-essential workplaces }\end{array}$ & March 18-24, 2020 \\
\hline $\begin{array}{l}\text { Closure of non-essential workplaces until the } \\
\text { first easing of restrictions }\end{array}$ & $\begin{array}{l}\text { March 24-May 16, } \\
2020\end{array}$ \\
\hline $\begin{array}{l}\text { Selected businesses and recreation services to } \\
\text { resume activity, followed by Stage 1 reopening }\end{array}$ & $\begin{array}{l}\text { May 16-June 12, } \\
2020\end{array}$ \\
\hline $\begin{array}{l}\text { Stage 2 reopening } \\
\text { Stage 3 reopening including school } \\
\text { resumption }\end{array}$ & $\begin{array}{l}\text { June 12-July 17, } \\
2020\end{array}$ \\
\hline $\begin{array}{l}\text { Modified Stage 2 effective in selected regions } \\
\text { July 17-October 10, } \\
2020\end{array}$ & $\begin{array}{l}\text { October 10- } \\
\text { November 23, 2020 }\end{array}$ \\
\hline $\begin{array}{l}\text { Lockdown of the Toronto and Peel health } \\
\text { regions and further enhanced measures across } \\
\text { Ontario }\end{array}$ & $\begin{array}{l}\text { November 23- } \\
\text { December 23a, 2020 }\end{array}$ \\
\hline $\begin{array}{l}\text { December 23, 2020 marked the end date of data fitting in this study. The phases listed are those } \\
\text { that most regions in the province followed; some phases were regionally-specific based on local } \\
\text { epidemiology }\end{array}$
\end{tabular}

We estimated the effectiveness of interventions implemented in terms of the contact rate, the probability of transmission per contact, the symptomatic case detection rate and the proportion of contacts traced, quarantined or isolated. The transmission dynamics model was fitted to cumulative reported cases (4) using data until December 23, 2020 and accounted for different public health interventions (detailed below). We estimated daily individual contact rates between 2.66 and 12.17 contacts per day from March to December 2020. The estimated transmission probability per contact $\beta$ varied between 0.11 and 0.14 . The estimated quarantine proportion $q$ remained close to
$40 \%$ as of December 23. The rate of detection and isolation of symptomatic cases $\delta_{I}$ was estimated to be approximately $0.14 /$ day. Further details on the parameter estimates and their time evolution are presented in Figure 1.

\section{Figure 1: Parameters estimated by model fitting to cumulative reported cases in Ontario in 2020}

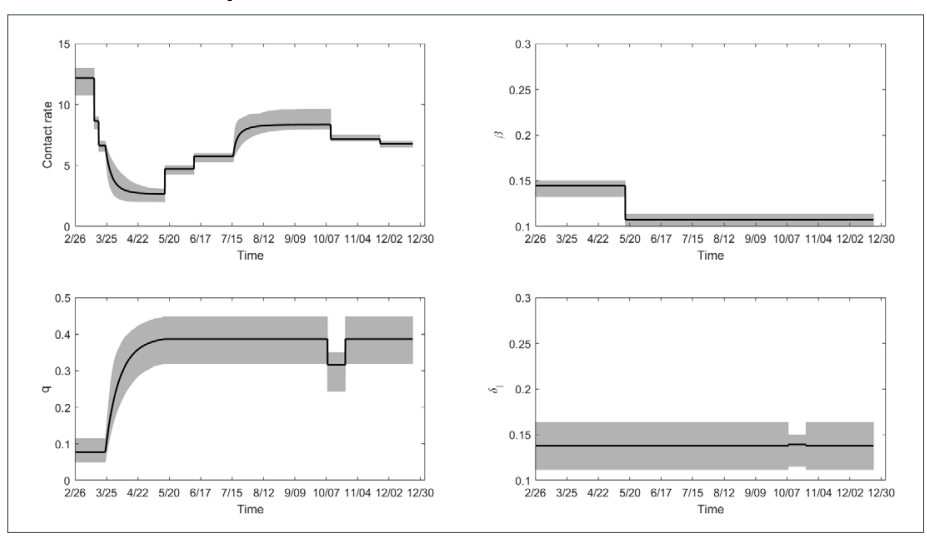

Note: The transmission probability per contact $\beta$ varied between 0.11 and 0.14 (top right), while the quarantine proportion $q$ remained close to $40 \%$ after the first wave (bottom left). The daily average contact rates, which identify the different phases of implementation/lifting of restrictive closures (top left) were: prior to March 14: $c=12.17$; March 14-18: $c=8.65$; March 18-24: $c=6.64$; May 16 (end of phase 3): $c=2.66$; May 16-June 12 (Stage 1 reopening): $c=4.72$; June 12-July 17 (Stage 2 reopening): $c=5.77$; October 10 (end of Stage 3 reopening): $c=8.36$; October 10-November 23 (modified Stage 2, enhanced measures): $c=7.14$; November 23-December 23 (lockdown in Toronto and Peel regions, further enhanced measures): $c=6.78$. The rate of detection and isolation of symptomatic cases $\delta$, remained at approximately $0.14 /$ day for most of the period (bottom right), corresponding to approximately $45 \%$ of symptomatic cases being detected and isolated

\section{Feasibility of preventing a new outbreak with variants of concern}

We then investigated the influence of different parameter values on the control reproduction number $R_{c^{\prime}}$ and assessed the necessary contact tracing and quarantine levels required for epidemic control when the VOC (B.1.1.7 strain) is the dominating strain. We considered, in particular, variations in the quarantine proportion, the proportion of symptomatic cases detected and isolated, and the different daily contact rates covering the values observed during the first and second waves.

A graph of the values for $q$ (quarantine proportion) and $\beta$ (transmission probability per contact) at which $R_{c}=1$ is shown in Figure 2. These graphs separate the regions of parameters that do or do not allow to control the epidemic for daily contact rates between three and 12 people. We included the parameter estimates obtained during the first and second waves, with transmission probability per contact $(\beta)$ increased by $40 \%$ compared with the previously estimated values, to account for the increased transmissibility of the VOC. The full circle corresponds to $\beta=0.15$ (the lower estimate for the originally circulating virus, 0.11 , increased by $40 \%$ ), and the empty circle corresponds to $\beta=0.2$ (the highest estimate for the originally circulating virus, 0.14 , increased by $40 \%$ ). For the quarantine fraction, we considered the estimated value before December 23. Notably, in the case of a contact rate equal to eight (corresponding to the contact rate estimated in Stage 3 of 
reopening), increasing the quarantine proportion from $40 \%$ to $75 \%$ will allow the control reproduction number to remain below one even when VOC becomes dominant.

Figure 2: Boundary of values for the proportion of contacts traced and quarantined and the transmission probability

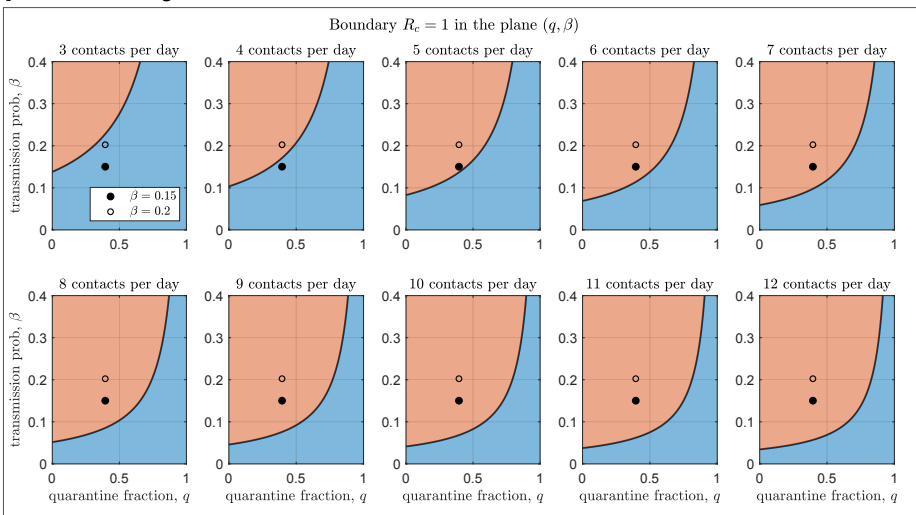

Note: The boundary of values for the proportion of contacts traced and quarantined $q$ and the transmission probability $\beta$ that determine whether the epidemic is controlled. The circles represent the parameters estimated by model fitting (quarantine proportion as of December 23,2020 , and the two estimated values of transmission probability increased by $40 \%$ due to the variants of concern, resulting in $\beta=0.15$ and $\beta=0.2$ ). The blue shaded area represents the parameter region that allows control, whereas the red shaded represents the region of epidemic spread

Similarly, we assessed the necessary contact tracing and quarantine, and case detection and isolation needed for epidemic control. A graph of the proportion of cases detected and isolated, and contacts traced and quarantined, at which $R_{c}=1$ is shown in Figure 3 . These graphs separate combinations of values for case detection and contact tracing that do and do not allow control of the epidemic. We estimated that a combination of $60 \%$ quarantine fraction and detection and isolation of $65 \%$ of symptomatic individuals is sufficient to prevent an outbreak using the contact rate estimated in Stage 2 of reopening ( $c=6$ contacts per day), even considering the highest estimate for the transmission probability (dashed lines in Figure 3).

\section{Discussion}

Using a transmission dynamics model fitted to cumulative reported COVID-19 cases in Ontario, we derived conditions under which a new wave could have been avoided despite the circulation of more transmissible VOCs. The fact that the province has experienced the third wave in the spring of 2021 shows that much could have been done in terms of testing-to-tracing and tracing-to-quarantine/isolation, along with physical distancing measures, to meet these conditions for reopening.

Our study shows that, if public health interventions can be sustained to ensure a declining trend in cases leading to a reduction of cases to a level such that testing capacity allows
Figure 3: Boundary of values for the proportion of contacts traced and quarantined and the proportion of symptomatic cases detected and isolated

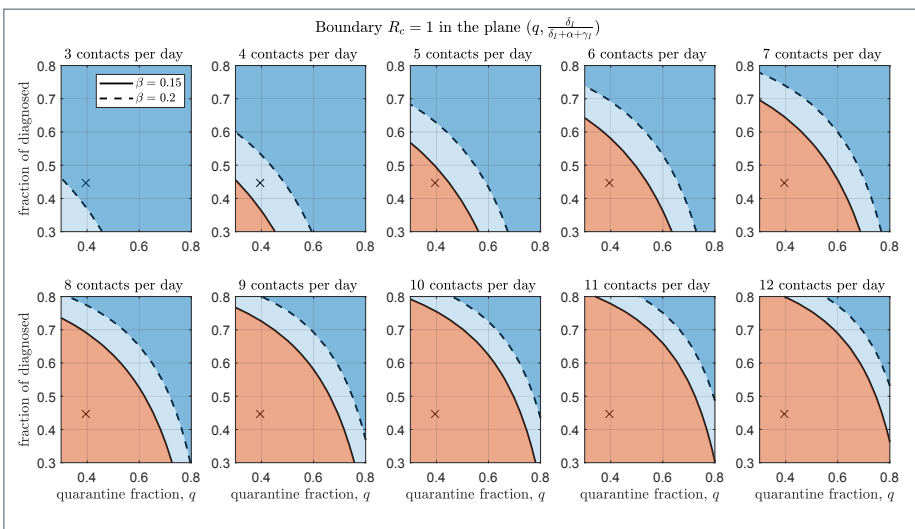

Note: The boundary of values for the proportion of contacts traced and quarantined $q$ and the proportion of symptomatic cases detected and isolated $\delta_{I} /\left(\delta_{l}+\alpha+Y_{1}\right)$ that determine whether the epidemic is controlled. The crosses represent the parameters estimated by model fitting until December 23, 2020. The solid and dashed curves represent the controllability threshold when the transmission probability $\beta$ is at the lower and higher estimated values, respectively. The blue shaded area represents the parameter region that allows control (light blue: control is possible only if transmissibility is at the lower value $\beta=0.15$; dark blue: control possible also for high transmissibility $\beta=0.2$ ), whereas the red shaded represents the region of epidemic spread

more complete detection of cases, and contact tracing is conducted effectively with a high proportion of exposed individuals quarantined (and both occur rapidly enough), prevention of a new outbreak is feasible even under the worst case scenario that VOC becomes dominant. However, based on our analysis, this requires substantial increase in the proportion of cases that are detected, and in the proportion of contacts that are traced and quarantined. Specifically, if the daily individual contact rate in Ontario returns to its estimated value in the Stage 2 reopening (approximately six contacts per day), then a new outbreak (the third wave) could have been prevented if, for each new 100 infections generated, 60 of the 100 individuals were traced and isolated before becoming infectious; and further, of those who are not traced and go on to develop symptoms, 65 out of 100 were tested, diagnosed and isolated. Alternatively, if the detection rates among symptomatic individuals remain at their current estimated levels (i.e. about 45 out of 100 symptomatic individuals who missed tracing are diagnosed), a contact rate estimated during Stage 3 reopening (between eight and nine contacts per day) would be sustainable if, out of 100 new infections generated, approximately 75 were traced and isolated before entering their infectious period.

These high quarantine and isolation proportions can be achieved only if case numbers are reduced to low levels, creating a narrow window of opportunity to prevent a new wave. This cascading effect was discussed previously (8). When focused and coherent mitigation interventions lead to an accelerated rate of case decline to a level that reopening can start with a very small number of new infections, effective public health mitigation interventions can and should be further mobilized for swift focused reaction to any new localized hotspot, avoiding a full-scale subsequent wave in the presence of VOC. These 
studies show that decision for reopening must take consideration of not only the decline rate of cases and case numbers, but the public health capacity for testing, tracing, quarantine and isolation. This is particularly relevant for any province that is implementing lockdown measures to mitigate an ongoing wave: creating the conditions for reopening must involve the enhancement of testing-to tracing and the follow-up quarantine and isolation logistics.

\section{Strengths and limitations}

Our study demonstrates that increased efforts in public health policies of symptomatic case detection and contact tracing could have allowed control of the epidemic even if a VOC with $40 \%$ increased transmissibility becomes dominant. One important advantage of our methodology is that it uses retrospective assessment and quantification of public health efforts (in terms of symptomatic diagnosis and quarantine of contacts) in the previous (first and second) COVID-19 epidemic waves, to estimate the necessary increase in effort to have prevented a third outbreak. However, our study is based on several assumptions, some of which could be easily relaxed, while others are specific to the chosen modelling framework. First, our estimates do not account for the decrease in the number of susceptible individuals due to infection-induced immunity or to the distribution of vaccines in the population; thus, they provide a somewhat conservative scenario. Moreover, we have here assumed a fixed increase (by $40 \%$ ) in the VOC transmissibility, representing the lower values estimated for the B.1.1.7 variant. The methodology could be easily adapted to study different levels of increased transmissibility, which may be more descriptive of other existing and emerging VOCs. Another important aspect is that the transmission model is based on the assumption of homogeneous mixing of individuals, thus ignoring heterogeneity due to different age or risk groups, behaviors or settings. Some level of heterogeneity, for example between different age groups and social settings, could be incorporated in the model by using stratified compartments, although this comes at the cost of increased complexity in parameter estimation (9). Other levels of heterogeneity, for instance spatial heterogeneity or clusters of transmission, would require more complex modelling approaches. Another limitation is that we fitted the model to laboratory confirmed cases. While having the advantage of being widely accessible and timely, these data sets could be biased by several factors including temporal variations in daily tests or in testing protocols.

\section{Conclusion}

We have identified conditions under which a new wave (the third wave) could have been prevented in Ontario, considering the worst case that the more transmissible B.1.1.7 strain became dominant. Our analysis indicates that high levels of case isolation and quarantine would have been needed to maintain control to ensure a safe partial reopening. While this study focused on the prevention of the third wave in Ontario, the approach presented herein is amenable to be adapted to other geographic regions and circumstances. Several assumptions made in the mathematical model can be relaxed for a potentially more accurate assessment. The analysis of the control reproduction number $R_{c^{\prime}}$ informed by model fitting and emerging evidence, may be used to identify estimates of conditions in terms of measures from the public health system and activity levels in the population needed for controllability. In this light, results obtained by utilizing this approach may be helpful for decision-makers posed with questions of reopening given the emergence of additional variants of the SARS-CoV-2 virus with increased transmissibility.

\section{Authors' statement}

$\mathrm{JW}$ and $\mathrm{NHO}$ - Conceived the original idea

$Z M C$ and YX - Performed the model fit

ZMC and FS - Curated the mathematical analysis and visualization

All authors discussed the results and contributed to the final manuscript.

\section{Competing interests}

None.

\section{Funding}

This research of ZMC, FS and JW was funded by the Canadian Institute of Health Research (CIHR) 2019 Novel Coronavirus (COVID-19) rapid research program. JW is a member of the Ontario COVID-19 Modelling Consensus Table, sponsored by the Ontario Ministry of Health, Ontario Health, and Public Health Ontario.

\section{References}

1. Ogden $\mathrm{NH}$, Fazil $A$, Arino J, Berthiaume $P$, Fisman DN, Greer AL, Ludwig A, Ng V, Tuite AR, Turgeon P, Waddell LA, Wu J. Modelling scenarios of the epidemic of COVID-19 in Canada. Can Commun Dis Rep 2020;46(8):198-204. DOI PubMed

2. Ng V, Fazil A, Waddell LA, Bancej C, Turgeon P, Otten A, Atchessi N, Ogden NH. Projected effects of nonpharmaceutical public health interventions to prevent resurgence of SARS-CoV-2 transmission in Canada. CMAJ 2020;192(37):E1053-64. DOI PubMed

3. Ludwig A, Berthiaume P, Orpana H, Nadeau C, Diasparra M, Barnes J, Hennessy D, Otten A, Ogden N. Assessing the impact of varying levels of case detection and contact tracing on COVID-19 transmission in Canada during lifting of restrictive closures using a dynamic compartmental model. Can Commun Dis Rep 2020;46(11-12):409-21. DOI PubMed 
4. Tang B, Scarabel F, Bragazzi NL, McCarthy Z, Glazer M, Xiao Y, Heffernan JM, Asgary A, Ogden NH, Wu J. De-Escalation by Reversing the Escalation with a Stronger Synergistic Package of Contact Tracing, Quarantine, Isolation and Personal Protection: Feasibility of Preventing a COVID-19 Rebound in Ontario, Canada, as a Case Study. Biology (Basel) 2020;9(5):100. DOI PubMed

5. Tuite AR, Fisman DN, Greer AL. Mathematical modelling of COVID-19 transmission and mitigation strategies in the population of Ontario, Canada. CMAJ 2020;192(19):E497-505. DOI PubMed

6. Volz E, Mishra S, Chand M, Barrett JC, Johnson R, Geidelberg L, Hinsley WR, Laydon DJ, Dabrera G, O'Toole A, Amato R, Ragonnet-Cronin M, Harrison I, Jackson B, Ariani C, Boyd O, Loman NJ, McCrone JT, Goncalves S, Jorgensen D, Myers R, Hill V, Jackson DK, Gaythorpe K, Groves N, Sillitoe J, Kwiatkowski DP; The COVID-19 Genomics UK (COG-UK) Consortium. Flaxman S, Ratmann O, Bhatt S, Hopkins S, Gandy A, Rambaut A, Ferguson NM. Transmission of SARS-CoV-2 Lineage B. 1.1. 7 in England: Insights from linking epidemiological and genetic data. Virological.org 2020. https://virological.org/t/transmissionof-sars-cov-2-lineage-b-1-1-7-in-england-insights-fromlinking-epidemiological-and-genetic-data/576
7. Davies NG, Abbott S, Barnard RC, Jarvis Cl, Kucharski AJ, Munday J, Pearson CAB, Russel TW, Tully DC, Abbott S, Gimma a, Waites W, Wong KLM, van Zandvoort, CMMID COVID-19 Working Group, Eggo RM, funk S, Jit M, Atkins KE, Edmunds WJ. Estimated transmissibility and severity of novel SARS-CoV-2 Variant of Concern 202012/01 in England. medRxiv 2020.12.24.20248822. DOI

8. Wu J, Tang B, Xiao Y, Tang S, Ahmad A, Orbinski J. Swift mitigations and tipping point cascade effects: Rethinking COVID-19 control and prevention measures to prevent and limit future outbreaks. Health Management Policy and Innovation. 2020;5(1), Special issue on COVID-19. https:// hmpi.org/2020/12/17/swift-mitigations-and-tipping-pointcascade-effects-rethinking-covid-19-control-and-preventionmeasures-to-prevent-and-limit-future-outbreaks-york-xianjiaotong-shaanxi-normal-12-7/?pdf=2987

9. McCarthy Z, Xiao Y, Scarabel F, Tang B, Bragazzi NL, Nah K, Heffernan JM, Asgary A, Murty VK, Ogden NH, Wu J.

Quantifying the shift in social contact patterns in response to non-pharmaceutical interventions. J Math Ind 2020;10(1):28. DOI PubMed 


\section{Appendix: Details of the transmission dynamics model}

\section{Background}

A central component of the intervention used to quantify conditions that combined public health interventions must meet to reopen the economy without a large outbreak is a transmission dynamics model. Here we provide details of the application of the transmission dynamics model established in prior study (10) to the present study, which enabled the calculations of the control reproduction number $R_{c}$ under the scenarios presented in the main text (Figure 2 and Figure 3 in the main text). The key step for the established model's usage in the analysis of $R_{c}$ is the model parametrization (i.e. estimating the model parameters using Ontario-specific incidence data until December 23, 2020). In this Appendix, we present the complete methods used for the model parametrization and detailed results from the model fitting. This model parameterization allowed for the estimation of the needed enhancements to public health interventions in terms of tracing and quarantine, and detection and isolation for a reopening amid the circulation of variants of concern (VOCs).

\section{Transmission model}

We utilized the transmission dynamics model established in a prior study (10), which captures essential epidemic features and key public health interventions including contact tracing, quarantining, testing and isolation. The model variables, key model parameters and their descriptions are presented in the main text of the article. In addition, we note that the quarantined individuals can either move to the compartment $E_{q}$ or $S_{q^{\prime}}$ depending on whether transmission occurred (with transmission probability per contact $\beta$ ), while the other proportion, $1-q$, comprises individuals exposed to the virus who are missed by contact tracing and, therefore, move to the compartment for those exposed and infected but not quarantined $(E)$ if transmission occurred, or stay in the compartment $S$ otherwise.

Here, we present the mathematical model equations and details of its parameterization. The transmission dynamics model was formulated in terms of ordinary different equations:

$$
\begin{aligned}
& S^{\prime}=-(\beta c+c q(1-\beta)) S(I+\theta A) / N+\lambda S_{q}, \\
& E^{\prime}=\beta c(1-q) S(I+\theta A) / N-\sigma E, \\
& I^{\prime}=\sigma \varrho E-\left(\delta_{I}+\alpha+\gamma_{I}\right) I, \\
& A^{\prime}=\sigma(1-\varrho) E-\gamma_{A} A, \\
& S_{q}^{\prime}=(1-\beta) \operatorname{cq} S(I+\theta A) / N-\lambda S_{q}, \\
& E_{q}^{\prime}=\beta c q S(I+\theta A) / N-\delta_{q} E_{q}, \\
& D^{\prime}=\delta_{I} I+\delta_{q} E_{q}-\left(\alpha+\gamma_{D}\right) D, \\
& R^{\prime}=\gamma_{I} I+\gamma_{A} A+\gamma_{D} D,
\end{aligned}
$$

\begin{tabular}{|c|c|c|c|c|c|}
\hline \multicolumn{2}{|c|}{ Parameter } & Definitions & Mean & Std & Source \\
\hline \multirow{11}{*}{$c(t)$} & $c_{0}$ & $\begin{array}{l}\text { Contact rate before March } \\
14,2020\end{array}$ & 12.17 & 0.6172 & Estimated \\
\hline & $c_{1}$ & $\begin{array}{l}\text { Contact rate between March } \\
14 \text { to March } 182020\end{array}$ & 8.65 & 0.2696 & Estimated \\
\hline & $c_{2}$ & $\begin{array}{l}\text { Constant contact rate on } \\
\text { March 24, } 2020\end{array}$ & 6.64 & 0.1922 & Estimated \\
\hline & $r_{1}$ & $\begin{array}{l}\text { Exponential decrease of } \\
\text { contact rate between March } 24 \\
\text { and May } 16,2020\end{array}$ & 0.1936 & 0.1086 & Estimated \\
\hline & $c_{b}$ & $\begin{array}{l}\text { Minimum contact rate after } \\
\text { March 24, } 2020\end{array}$ & 2.66 & 0.3314 & Estimated \\
\hline & $c_{3}$ & $\begin{array}{l}\text { Contact rate between May } 16 \\
\text { to June } 12,2020\end{array}$ & 4.72 & 0.2224 & Estimated \\
\hline & $c_{4}$ & $\begin{array}{l}\text { Contact rate between June } 12 \\
\text { to July } 17,2020\end{array}$ & 5.77 & 0.4068 & Estimated \\
\hline & $c_{m}$ & $\begin{array}{l}\text { Maximum contact rate } \\
\text { between July } 17 \text { and October } \\
10,2020\end{array}$ & 8.36 & 0.2605 & Estimated \\
\hline & $r_{3}$ & $\begin{array}{l}\text { Exponential increase of contact } \\
\text { rate between July } 17 \text { and } \\
\text { October } 10,2020\end{array}$ & 0.3117 & 0.0032 & Estimated \\
\hline & $c_{5}$ & $\begin{array}{l}\text { Contact rate between October } \\
10 \text { to November } 23,2020\end{array}$ & 7.14 & 0.1299 & Estimated \\
\hline & $c_{6}$ & $\begin{array}{l}\text { Contact rate between } \\
\text { November } 23 \text { to December } \\
23,2020\end{array}$ & 6.78 & 0.1746 & Estimated \\
\hline \multicolumn{2}{|c|}{$\beta_{1}$} & $\begin{array}{l}\text { Probability of transmission per } \\
\text { contact before May 16, } 2020\end{array}$ & 0.1446 & 0.0051 & Estimated \\
\hline \multicolumn{2}{|c|}{$\beta_{2}$} & $\begin{array}{l}\text { Probability of transmission per } \\
\text { contact after May 16, } 2020\end{array}$ & 0.1073 & 0.0076 & Estimated \\
\hline \multicolumn{2}{|c|}{$q_{0}$} & $\begin{array}{l}\text { Fraction of quarantined } \\
\text { exposed individuals before } \\
\text { March 24, } 2020\end{array}$ & 0.0775 & 0.0177 & Estimated \\
\hline \multirow{3}{*}{$q(t)$} & $r_{2}$ & $\begin{array}{l}\text { Exponential increase of } \\
\text { quarantine fraction }\end{array}$ & 0.0835 & 0.0314 & Estimated \\
\hline & $q_{b}$ & $\begin{array}{l}\text { The maximum quarantine } \\
\text { fraction before October } 8 \text {, } \\
2020\end{array}$ & 0.3949 & 0.0334 & Estimated \\
\hline & $q_{1}$ & $\begin{array}{l}\text { The quarantine fraction } \\
\text { between October } 8 \text { and } \\
\text { October 22, } 2020\end{array}$ & 0.3156 & 0.0368 & Estimated \\
\hline \multicolumn{2}{|c|}{$\sigma$} & $\begin{array}{l}\text { Transition rate of exposed } \\
\text { individuals to the infected class }\end{array}$ & $1 / 5$ & 0 & (11) \\
\hline \multicolumn{2}{|c|}{$\lambda$} & $\begin{array}{l}\text { Rate at which the quarantined } \\
\text { uninfected contacts were } \\
\text { released into the wider } \\
\text { community }\end{array}$ & $1 / 14$ & 0 & $(12)$ \\
\hline \multicolumn{2}{|c|}{$\varrho$} & $\begin{array}{l}\text { Probability of developing } \\
\text { symptoms among infected } \\
\text { individuals }\end{array}$ & 0.7240 & 0.0278 & Estimated \\
\hline \multicolumn{2}{|c|}{$\delta_{1}$} & $\begin{array}{l}\text { Transition rate of symptomatic } \\
\text { infected individuals to the } \\
\text { quarantined infected class }\end{array}$ & 0.1378 & 0.0133 & Estimated \\
\hline \multicolumn{2}{|c|}{$\delta_{I 1}$} & $\begin{array}{l}\text { Transition rate of symptomatic } \\
\text { infected individuals to the } \\
\text { quarantined infected class } \\
\text { between October } 8 \text { and } \\
\text { October } 22,2020\end{array}$ & 0.1392 & 0.0100 & Estimated \\
\hline \multicolumn{2}{|c|}{$\delta_{q}$} & $\begin{array}{l}\text { Transition rate of quarantined } \\
\text { exposed individuals to the } \\
\text { quarantined infected class }\end{array}$ & 0.1217 & 0.0301 & Estimated \\
\hline
\end{tabular}

where the prime symbol (') denotes the derivative with respect to time. The full list of model parameters and their descriptions is included in Table 1.
Table 1: Estimated parameter values for the COVID-19 transmission dynamics model in Ontario, Canada 
Table 1: Estimated parameter values for the COVID-19 transmission dynamics model in Ontario, Canada (continued)

\begin{tabular}{|c|l|r|r|l|}
\hline Parameter & \multicolumn{1}{|c|}{ Definitions } & Mean & \multicolumn{1}{c|}{ Std } & Source \\
\hline$Y_{I}$ & $\begin{array}{l}\text { Recovery rate of symptomatic } \\
\text { infectious individuals }\end{array}$ & 0.1627 & 0.0164 & Estimated \\
\hline$Y_{A}$ & $\begin{array}{l}\text { Recovery rate of asymptomatic } \\
\text { infectious individuals }\end{array}$ & 0.139 & 0 & $(12)$ \\
\hline$Y_{D}$ & $\begin{array}{l}\text { Recovery rate of quarantined } \\
\text { diagnosed individuals }\end{array}$ & 0.2 & 0 & $(13)$ \\
\hline$\alpha$ & Disease-induced death rate & 0.008 & 0 & $(13)$ \\
\hline$\theta$ & $\begin{array}{l}\text { Modification factor of } \\
\text { asymptomatic infectiousness }\end{array}$ & 0.0342 & 0.0068 & Estimated \\
\hline
\end{tabular}

We obtained the control reproduction number $R_{c}$ of the above transmission model using the next generation method (14). In the analysis of the control reproduction number $R_{c}$ in this study, we did not account for the decrease in the susceptible population due to infection-induced immunity or vaccination and assumed that $S(t) / N(t)=1$. The resultant control reproduction number is:

$$
R_{c}=\frac{\beta \rho c(1-q)}{\delta_{I}+\alpha+\gamma_{I}}+\frac{\beta c \theta(1-\rho)(1-q)}{\gamma_{A}}
$$

To then estimate the model parameters from February 26, 2020 until December 23, 2020, we used the following process. We first considered the parameters $\theta, \lambda, \sigma, \rho, Y_{A^{\prime}} Y_{p} \delta_{\alpha^{\prime}} Y_{D^{\prime}} \alpha$ as constant in time. On the other hand, we considered several model parameters as time-dependent based on the Ontario timeline of key events, intervention implementations and relaxations (detailed in the main text of the article): the contact rate $c$, the quarantine proportion $q$, the probability of transmission per contact $\beta$, and the symptomatic detection rate $\delta_{1}$.

We allowed the contact rate $c$ to change according to the timeline of public health interventions implemented in the Province. Specifically, we assumed the following piecewise form for the contact rate:

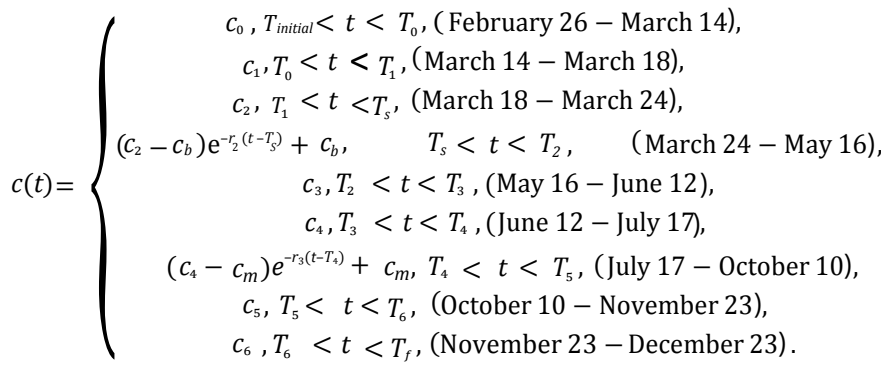

where $T_{\text {initial }} T_{0^{\prime}}, T_{1}, T_{s^{\prime}} T_{2^{\prime}} T_{3}, T_{4^{\prime}}, T_{5^{\prime}}, T_{6^{\prime}}, T_{f}$, correspond to times matching the dates February 26, 2020, March 14, 2020, March 18, 2020, March 24, 2020, May 16, 2020, June 12, 2020, July 17 2020, October 10, 2020, November 23, 2020 and December 23, 2020, respectively. These dates correspond to key dates detailed in the main text of the article. An exponential function was used to capture society's gradual adaptation to stricter or looser control measures during the non-essential workplace closure and Stage 3 reopening.

To estimate the resultant potential change in transmission risk per contact over time, we modelled the transmission probability per contact $\beta$ using the following piecewise constant function:

$$
\beta(t)=\left\{\begin{array}{l}
\beta_{1}, T_{\text {initial }}<t<T_{\text {May16 }},(\text { February } 26-\text { May 16), } \\
\beta_{2}, T_{\text {May16 }}<t<T_{f}, \quad(\text { May } 16-\text { December 23), }
\end{array}\right.
$$

where $T_{\text {May16 }}$ corresponds to the date May 16, 2020 which marked the first easing of restrictions in Ontario.

We also allowed for alteration in the symptomatic detection rate during the dates October 8, 2020-October 22, 2020 to capture variations in testing, contact tracing and case detection during this period. The symptomatic detection rate $\delta_{I}$ we modelled as piecewise constant, with the form:

$$
\delta_{\mathrm{I}}(t)=\left\{\begin{array}{l}
\delta_{I}, T_{\text {initial }}<t<T_{\text {oct8 }},(\text { February } 26 \text { - October } 8), \\
\delta_{11}, T_{\text {oct8 }}<t<T_{\text {Oct22 }},(\text { October } 8 \text { - October 22), } \\
\delta_{I}, T_{\text {oct22 }}<t<T_{f},(\text { October } 22 \text { - December 23), }
\end{array}\right.
$$

where the dates $T_{\text {initial }} \mathrm{T}_{f^{\prime}}$ are defined above and $T_{\text {oct8 }}, T_{O_{\text {oct22 }}}$ correspond to the dates October 8, 2020 and October 22, 2020, respectively.

Finally, the quarantine proportion was also modelled as time-dependent. We captured here the escalation of tracing efforts from the public health system after the non-essential workplace closure on March 24, 2020 with a modelled exponential increase in $q$. Similar to the detection rate, we also allowed for variation in quarantine proportion $q$ between the dates October 8, 2020-October 22, 2020. The quarantine proportion was modelled as:

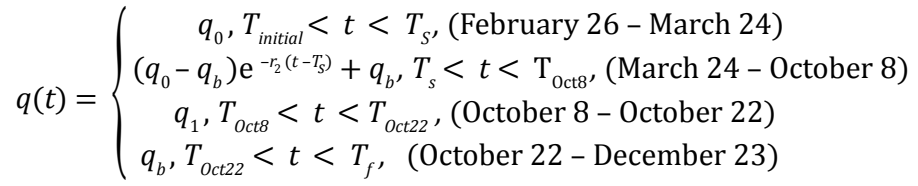

With the model and its parameters now associated with a suitable form permitting us to capture key elements in the Ontario timeline, we next incorporated the coronavirus disease 2019 (COVID-19) data coupled with a model fitting procedure to quantify the model parameter values.

\section{Data}

To parameterize the transmission model, we utilized the confirmed positive cases of COVID-19 in Ontario and population demographic data for Ontario. The time series of the cumulative cases of COVID-19 in Ontario was generated using individual line listed data from the Ontario Ministry of Health, which was 
made available to us through the Ontario COVID-19 Modeling Consensus Table. Second, the demographic data specific to Ontario in terms of the population size is available publicly by Statistics Canada (15). These were the main sources of data which enabled the fitting of mathematical model and the subsequent analyses.

\section{Model fitting}

To estimate the model parameters, we fit the transmission model the cumulative incidence of confirmed COVID-19 cases in Ontario. The fitting technique utilized has been outlined in prior study (10) and is summarized as follows: we informed the model with estimated parameters $\alpha, Y_{A}$ from existing studies (Table 1), the necessary population size data from Statistics Canada (15) and the initial conditions (Table 2). We then run the model forward from $t=T_{\text {initial }}$ to $T_{f}$ (February 26, 2020 to December 23, 2020), and determined the parameters which minimized the least square error against the cumulative incidence. Confidence intervals for parameters were estimated by employing a bootstrap method to generate 1,000 cumulative incidence time series (10). It was assumed that the newly reported cases followed a Poisson distribution, and the model was fitted to each of the 1,000 realizations of the observed time series. The process yielded 1,000 sets of parameters values for $q$, $Y_{I}, \delta_{I}, \theta, C, \beta, \rho$, and the estimated mean and standard deviation for each are reported in Table 1. For non-fitted parameters $\alpha, Y_{A^{\prime}}$ the source is reported.

Table 2: Estimated initial values for the COVID-19 transmission dynamics model in Ontario, Canada

\begin{tabular}{|c|c|c|c|c|}
\hline $\begin{array}{l}\text { Initial } \\
\text { values }\end{array}$ & Definitions & Mean & Std & Source \\
\hline$S(0)$ & $\begin{array}{l}\text { Initial susceptible } \\
\text { population }\end{array}$ & $1.471 \times 10^{7}$ & 0 & Data (15) \\
\hline$E(0)$ & $\begin{array}{l}\text { Initial exposed } \\
\text { population }\end{array}$ & 16.0081 & 4.9432 & Estimated \\
\hline$I(0)$ & $\begin{array}{l}\text { Initial symptomatic } \\
\text { infectious population }\end{array}$ & 12.2829 & 3.7544 & Estimated \\
\hline$A(0)$ & $\begin{array}{l}\text { Initial asymptomatic } \\
\text { infectious population }\end{array}$ & 14.2352 & 6.1958 & Estimated \\
\hline$S_{q}(0)$ & $\begin{array}{l}\text { Initial quarantined } \\
\text { susceptible } \\
\text { population }\end{array}$ & 0 & 0 & Assumed \\
\hline$E_{q}(0)$ & $\begin{array}{l}\text { Initial quarantined } \\
\text { exposed population }\end{array}$ & 0 & 0 & Assumed \\
\hline$D(0)$ & $\begin{array}{l}\text { Initial quarantined } \\
\text { diagnosed population }\end{array}$ & 5 & 0 & $\begin{array}{l}\text { Incidence } \\
\text { data }\end{array}$ \\
\hline$R(0)$ & $\begin{array}{l}\text { Initial recovered } \\
\text { population }\end{array}$ & 0 & 0 & Assumed \\
\hline
\end{tabular}

Abbreviation: COVID-19, coronavirus disease 2019; Std, standard deviation
The model fit and quantified uncertainty against the true case data in Ontario is shown in Figure 1 in terms of the daily reported cases (top right) and cumulative reported cases (top left); the estimated number of active symptomatic infectious individuals $I(t)$ (bottom left) and estimated number of active asymptomatic infectious individuals $A(t)$ (bottom right) and their time evolution are also depicted. The values (including $95 \% \mathrm{Cls}$ ) and time evolution of the key parameters $\beta, \delta_{I^{\prime}} q, C$ are shown in Figure 1 in the main text.

\section{Figure 1: Model fit results}

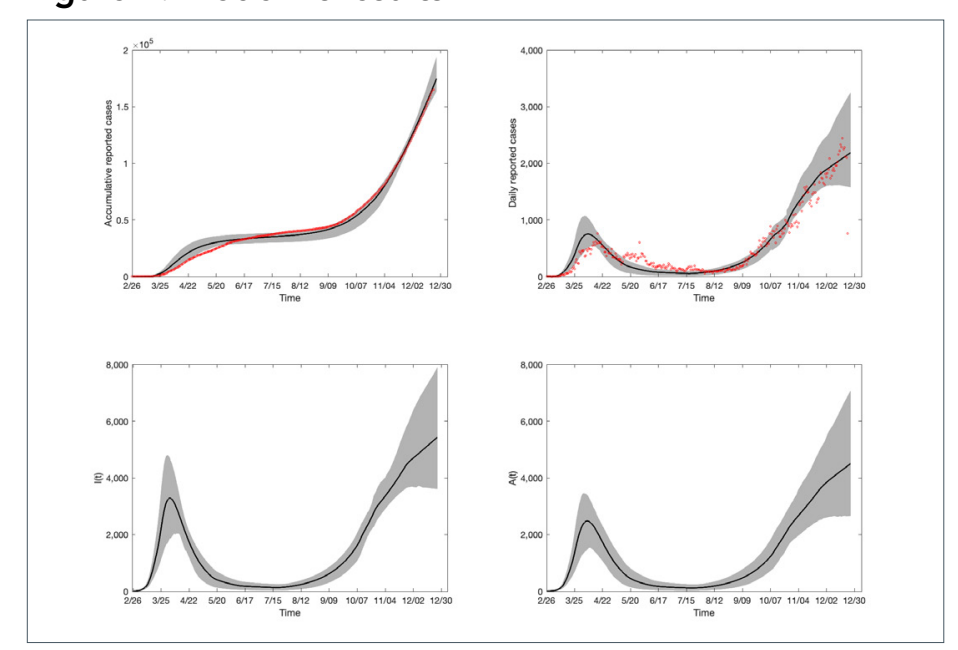

Note: (Top left) Model fit against cumulative reported COVID-19 cases in Ontario as of December 23,2020 . The red dots represent the observed cumulative reported cases, whereas the black line denotes the mean of the 1,000 model runs and the grey shaded region representing the $95 \%$ confidence interval (Cl). (Top right) Model fit against the daily reported cases in Ontario as of December 23,2020 . The red dots represent the daily number of reported cases in the province. (Bottom left) The estimated number of symptomatic infectious individuals as produced by the fitted model and the $95 \% \mathrm{Cl}$. (Bottom right) The estimated number of active asymptomatic infectious individuals in Ontario as produced by the fitted model, as well as the corresponding $95 \% \mathrm{Cl}$

\section{Application}

We have estimated the transmission model parameters as of December 23, 2020, which completely informed the control reproduction number $R_{c}$. To incorporate the effects of VOCs in the analysis of $R_{c^{\prime}}$ we integrated existing estimates of the increased transmissibility of the B.1.1.7 strain first identified in the United Kingdom $(16,17)$ and increased the estimated values for $\beta$ by $40 \%$, as detailed in the main text. We then assessed $R_{c}$ under different scenarios corresponding to the proportion of symptomatic individuals who are tested, confirmed and isolated during their infectious period $\delta_{I} /\left(\delta_{I}+\alpha+Y_{I}\right)$, the proportion of contacts traced and quarantined $(q)$, the transmission probability per contact $(\beta)$, and contact rate $(c)$ by altering the parameters $\delta_{l}, q, \beta, c$, accordingly. The main study outcomes in terms of conditions on the enhanced public health measures (Figure 2 and Figure 3 in the main text) needed to maintain $R_{c}<1$ were generated by effectively viewing $R_{c}$ as a function of $\beta, \delta_{I}, c, q$. Thus, we identified the needed levels of (enhanced) controls to prevent a VOC wave while achieving contact rates that were estimated during different phases of public health interventions in Ontario. 


\section{References}

10. Tang B, Scarabel F, Bragazzi NL, McCarthy Z, Glazer M, Xiao Y, Heffernan JM, Asgary A, Ogden NH, Wu J.

De-Escalation by Reversing the Escalation with a Stronger Synergistic Package of Contact Tracing, Quarantine, Isolation and Personal Protection: Feasibility of Preventing a COVID-19 Rebound in Ontario, Canada, as a Case Study. Biology (Basel) 2020;9(5):100. DOI PubMed

11. Special Expert Group for Control of the Epidemic of Novel Coronavirus Pneumonia of the Chinese Preventive Medicine Association. [An update on the epidemiological characteristics of novel coronavirus pneumonia (COVID-19)]. Zhonghua Liu Xing Bing Xue Za Zhi 2020;41(2):139-44. DOI PubMed

12. Tang B, Wang $X$, Li Q, Bragazzi NL, Tang S, Xiao Y, Wu J. Estimation of the transmission risk of the 2019-nCoV and its implication for public health interventions. J Clin Med 2020;9(2):462. DOl PubMed

13. Tang B, Xia F, Tang S, Bragazzi NL, Li Q, Sun X, Liang J, Xiao Y, Wu J. The effectiveness of quarantine and isolation determine the trend of the COVID-19 epidemics in the final phase of the current outbreak in China. Int J Infect Dis 2020;95:288-93. DOI PubMed
14. van den Driessche P. Reproduction numbers of infectious disease models. Infect Dis Model 2017;2(3):288-303. DOI PubMed

15. Statistics Canada. Table 17-10-0009-01 Population estimates, quarterly. 2020. https://www150.statcan.gc.ca/t1/ tbl1/en/tv.action?pid=1710000901

16. Volz E, Mishra S, Chand M, Barrett JC, Johnson R, Geidelberg L, Hinsley WR, Laydon DJ, Dabrera G, O'Toole A, Amato R, Ragonnet-Cronin M, Harrison I, Jackson B, Ariani C, Boyd O, Loman NJ, McCrone JT, Goncalves S, Jorgensen D, Myers R, Hill V, Jackson DK, Gaythorpe K, Groves N, Sillitoe J, Kwiatkowski DP; The COVID-19 Genomics UK (COG-UK) Consortium. Flaxman S, Ratmann O, Bhatt S, Hopkins S, Gandy A, Rambaut A, Ferguson NM. Transmission of SARS-CoV-2 Lineage B. 1.1. 7 in England: Insights from linking epidemiological and genetic data. Virological.org 2020. https://virological.org/t/ transmission-of-sars-cov-2-lineage-b-1-1-7-in-englandinsights-from-linking-epidemiological-and-genetic-data/576

17. Davies NG, Abbott S, Barnard RC, Jarvis Cl, Kucharski AJ, Munday J, Pearson CAB, Russel TW, Tully DC, Abbott $S$, Gimma A, Waites W, Wong KLM, van Zandvoort, CMMID COVID-19 Working Group, Eggo RM, funk S, Jit M, Atkins KE, Edmunds WJ. Estimated transmissibility and severity of novel SARS-CoV-2 Variant of Concern 202012/01 in England. medRxiv 2020.12.24.20248822. DOI

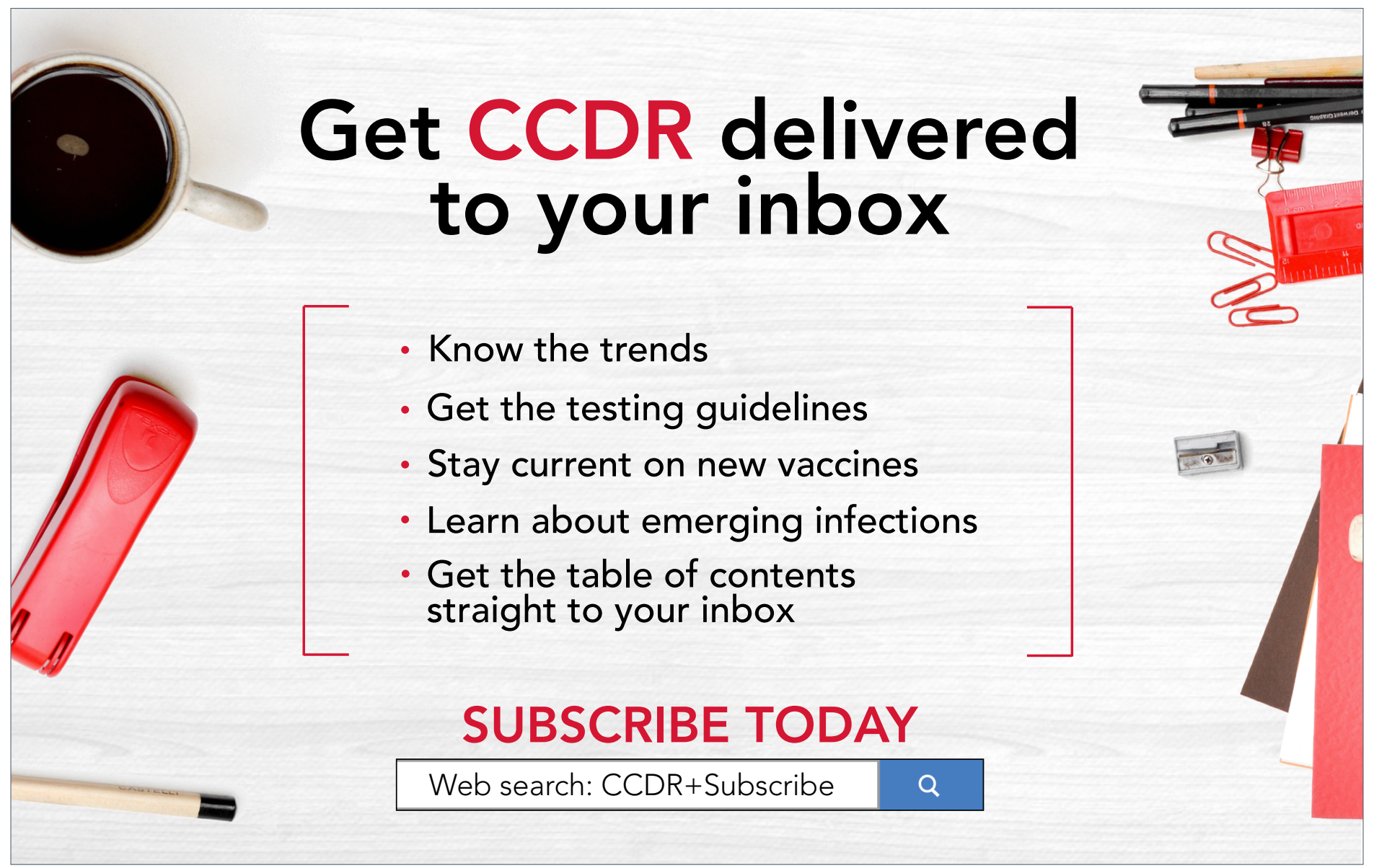

